\title{
The effects of a high fibre, low fat and low sodium dietary regime on diabetic hypertensive patients of different ethnic groups
}

\author{
P. M. DODSON \\ M.B., M.R.C.P. \\ P. J. PACY \\ M. BEEVERS \\ S.R.N. \\ M.B., M.R.C.P. \\ P. BAL \\ B.Sc., S.R.D. \\ R. F. FLETCHER \\ M.D., Ph.D., F.R.C.P. \\ K. G. TAYLOR \\ M.D., M.R.C.P. \\ Department of Diabetes and Endocrinology, and Clinical Investigation Unit, Dudley Road Hospital, Birmingham
}

\section{Summary}

Fifty-three diabetic patients with mild hypertension were allocated to a treatment diet with a high fibre, low fat and low sodium dietary regime or a control diet. After a 1-month treatment period, the modifieddiet treated group $(n=35)$ showed a highly significant reduction in mean diastolic blood pressure $(P<0.001)$ accompanied by significant reduction in urinary sodium excretion $(P<0-01)$. The mean values of diastolic pressure $(P<0.05)$ and urinary sodium/potassium ratio $(P<0.01)$ were also significantly reduced at 1 month compared to control. White $(n=16)$ and West Indian $(n=10)$ diabetic hypertensive patients demonstrated a similar significant hypotensive response $(P<0.05$ and $<0.01$ respectively) with reduction in urinary sodium excretion to the modified diet. In contrast, Asian patients demonstrated no significant changes.

Treatment of hypertension in diabetic subjects with a high fibre, low fat and low sodium dietary regimen may have a hypotensive response after a period of 1 month and there is a similar response in both black and white ethnic groups. Further observation of these patients will determine long-term response and compliance.

KEY WORDS: fibre, fat, sodium, hypertension, diabetes mellitus.

\section{Introduction}

Hypertension is common in diabetic patients (Christlieb et al., 1981; Barrett-Connor et al., 1981), but treatment may be unsatisfactory due to the adverse effects of antihypertensive drugs on diabetic control and lipid metabolism.

Recent studies in non-diabetic hypertensive sub- jects have suggested a possible alternative to drug therapy, consisting of a low dietary sodium intake, which may reduce diastolic blood pressure (Morgan et al., 1978; MacGregor et al., 1982a). A significant reduction in blood pressure may also occur with a low fat intake (Puska et al., 1983) or with a high potassium intake (MacGregor et al., 1982b). Combining these dietary measures in a high fibre, low fat and low sodium regime has also been reported to produce a significant reduction of systolic and diastolic blood pressure with reduction of antihypertensive drug therapy in non-diabetic hypertensives (Dodson et al., 1981a; Beard et al., 1982), and may be associated with improved glycaemic control in diabetic patients (Kiehm, Anderson and Ward, 1976; Dodson et al., 1981b). This dietary regime has also been shown in both insulin and non-insulin dependent diabetics to result in alterations in serum cholesterol containing lipoproteins which may contribute to an overall reduction in cardiovascular disease (Dodson et al., 1981b).

We have therefore studied the effects on blood pressure of a high fibre, low fat and low sodium dietary regime in diabetic hypertensive patients. Particular emphasis has been placed on the effects of this regime on different ethnic diabetic hypertensive groups, in view of the different reported responses of the non-diabetic hypertensive ethnic groups to antihypertensive treatment. For example, blacks, who have been shown to have lower mean plasma renin levels (Helmer and Judson, 1968), may be less sensitive to beta-blockers but more sensitive to diuretic therapy than whites. Furthermore, compliance may not be as satisfactory amongst the black compared to the white population (HDFP Cooperative Study, 1977). 
TABLE 1. Clinical details of patients studied

\begin{tabular}{|c|c|c|c|c|c|c|c|}
\hline & \multirow[b]{2}{*}{$\begin{array}{l}\text { Number of } \\
\text { patients }\end{array}$} & \multirow[b]{2}{*}{ Sex } & \multirow[b]{2}{*}{$\begin{array}{c}\text { Mean age } \\
\text { (years) }\end{array}$} & \multirow{2}{*}{$\begin{array}{l}\text { Mean ideal } \\
\text { body weight } \\
\cdot \quad \text { (lb) }\end{array}$} & \multicolumn{3}{|c|}{$\begin{array}{l}\text { Hypoglycaemic therapy } \\
\text { (number of patients) }\end{array}$} \\
\hline & & & & & $\begin{array}{c}\text { Diet } \\
\text { alone }\end{array}$ & $\begin{array}{l}\text { Tablet } \\
\text { treated }\end{array}$ & $\begin{array}{l}\text { Insulin } \\
\text { treated }\end{array}$ \\
\hline Modified diet group & 35 & $\begin{array}{l}17 \mathrm{M} \\
17 \mathrm{~F}\end{array}$ & $53 \cdot 6 \pm 8 \cdot 5$ & $133 \cdot 5 \pm 18 \cdot 7$ & 21 & 12 & 1 \\
\hline White & 16 & $\begin{array}{l}9 \mathrm{M} \\
7 \mathrm{~F}\end{array}$ & $59 \pm 7 \cdot 71$ & $132 \cdot 7 \pm 18 \cdot 2$ & 10 & 5 & 1 \\
\hline West Indian & 10 & $\begin{array}{l}2 \mathrm{M} \\
8 \mathrm{~F}\end{array}$ & $51 \cdot 5 \pm 6 \cdot 3$ & $131 \cdot 2 \pm 16 \cdot 9$ & 6 & 4 & - \\
\hline Asian & 9 & $\begin{array}{l}4 \mathrm{M} \\
5 \mathrm{~F}\end{array}$ & $45 \cdot 8 \pm 5 \cdot 7$ & $127 \cdot 4 \pm 19 \cdot 9$ & 5 & 4 & - \\
\hline $\begin{array}{l}\text { Control (13 West Indian, } \\
3 \text { white, } 2 \text { Asian) }\end{array}$ & 18 & $\begin{array}{c}10 \mathrm{M} \\
8 \mathrm{~F}\end{array}$ & $55 \cdot 3 \pm 6 \cdot 7$ & $124 \cdot 8 \pm 18 \cdot 2$ & 9 & 6 & 3 \\
\hline
\end{tabular}

\section{Patients and methods}

Fifty-three diabetic hypertensive patients, attending the out-patients at Dudley Road Hospital, were studied. The clinical details of these patients are shown in Table 1.

Criteria for entry to this study were 3 consecutive hypertensive readings (as defined by the W.H.O.: systolic $\geqslant 160 \mathrm{mmHg}$ or diastolic $\geqslant 95 \mathrm{mmHg}$ ) in an established diabetic patient. Patients already receiving anti-hypertensive drug therapy were not excluded from the study provided World Health Organisation criteria for hypertension were met. No alteration to drug therapy was made during the trial period. Patients with evidence of diabetic or hypertensive nephropathy were excluded.

The patients were all treated previously on low carbohydrate diets which had been recommended by the hospital dietitian and had stable tablet or insulin therapy for at least 1 month before the study. Ten patients in the modified-diet treated group were established on antihypertensive drug therapy which was unchanged during the trial. The response to the modified dietary regimen was evaluated initially in 18 patients. Following this, patients were then allocated in a sequential fashion by the hospital dietitian to receive either the modified or the control diet.

At the beginning of the trial period, a 24-hr collection of urine, measurement of body weight and blood pressure was made. All patients were maintained on their diets and other treatment for 4 weeks, at the end of which time the initial observations were repeated. Blood pressure was recorded in the supine position after $5 \mathrm{~min}$ rest with a random zero Hawksley sphygmomanometer by a separate blind observer and the mean of 2 readings recorded. Diastolic blood pressure was recorded at the 5th Korotkoff phase.
The composition of the diet given to 35 of the patients compared to a normal western diet is shown in Table 2. The modified dietary regimen, made 40 from readily available western foodstuffs, consisted of high dietary fibre (35-40 g/day), high unrefined carbohydrate (65\% of total energy), low fat (15\% of total energy), low sodium (40-50 mmol/day), a ged normal potassium intake (70-80 mmol/day). Modi cations appropriate for the eating habits of the yest Indian and Asian patients were made to the of included in the dietary protocol. However, analy the modified diet was the same for all ethnic grofips.

Eighteen of the patients were allocated to the control group which consisted of continuing the्f former dietary regimen, but they otherwise followed the same trial protocol as the dietary modified group.

Statistics were by paired and unpaired $t$-test. Statistical differences between the number of patiens with normal blood pressure readings after 1 month were assessed by the chi-squared test.

\section{Results}

The changes in systolic and diastolic blood pressure, weight and 24-hr urinary sodium excretion, after a 1 -month period in the modified diet treated and control group are shown in Table 3. The modified-diet treated group showed a highly signifcant reduction in diastolic blood pressure $(P<0.00 \mathrm{~A})$, accompanied by a reduction of urinary sodiu output $(P<0.01)$ and urinary sodium/potassium ratio $(P<0.001)$. The diastolic blood pressufe $(P<0.05)$ and urinary sodium/potassium rafo $(P<0.01)$ of the diet treated group were also significantly lower compared to control values at 1 month. However, there was no significant change in weight, urinary potassium excretion, and systolic bloged pressure in both the modified diet treated and contfel treated groups. 
TABLE 2. Composition of the modified dietary regimen compared to a modern western diet

\begin{tabular}{lcc} 
& Trial diet & Modern western diet (U.S.A.) \\
\hline $\begin{array}{l}\text { Total energy } \\
\text { (kcal) }\end{array}$ & $\begin{array}{c}1600-1800 \\
(6 \cdot 5-7 \cdot 4 \mathrm{MJ})\end{array}$ & $\begin{array}{c}2100-4500 \\
(8 \cdot 6-18 \cdot 5 \mathrm{MJ})\end{array}$ \\
$\begin{array}{l}\text { Fat } \\
\quad \% \text { Total energy) }\end{array}$ & 15 & 42 \\
$\begin{array}{l}\text { Protein } \\
\quad \% \text { Total energy) }\end{array}$ & 20 & 12 \\
$\begin{array}{l}\text { Unrefined carbohydrate } \\
\quad \% \text { Total energy) }\end{array}$ & 65 & 22 \\
$\begin{array}{l}\text { Refined carbohydrate } \\
\quad \% \text { Total energy includes }\end{array}$ & & \\
$\quad$ alcohol intake) & $0-5$ & 24 \\
$\begin{array}{l}\text { Sodium (mmol/day) } \\
\text { Potassium (mmol/day) } \\
\text { Sodium/potassium ratio }\end{array}$ & $\begin{array}{c}40-50 \\
80-90\end{array}$ & $\simeq 180$ \\
\hline
\end{tabular}

TABLE 3. Changes in blood pressure, weight and urinary sodium excretion in the diet treated and control hypertensive diabetic patients (mean \pm s.d.)

\begin{tabular}{|c|c|c|c|c|}
\hline & \multicolumn{2}{|c|}{$\begin{array}{l}\text { Diet treated group } \\
\quad(n=35)\end{array}$} & \multicolumn{2}{|c|}{$\begin{array}{l}\text { Control } \\
(n=18)\end{array}$} \\
\hline & Time 0 & 1 month & Time 0 & 1 month \\
\hline Systolic blood pressure $(\mathrm{mmHg})$ & $173.8 \pm 23.8$ & $168 \cdot 5 \pm 22 \cdot 8$ & $169.7 \pm 18.2$ & $174 \cdot 1 \pm 18.9$ \\
\hline Diastolic blood pressure (mmHg) & $98.4 \pm 9.2$ & $91.7 \pm 8.9 \dagger$ & $94.4 \pm 7.3$ & $96.7 \pm 7.9$ \\
\hline Weight $(\mathbf{k g})$ & $74.95 \pm 13.7$ & $73.7 \pm 11.8$ & $73.3 \pm 16.6$ & $71.7 \pm 15.9$ \\
\hline Urinary sodium (24-hr output $\mathrm{mmol}$ ) & $195 \pm 78 \cdot 1$ & $136 \cdot 7 \pm 70 \cdot 2^{*}$ & $180 \cdot 2 \pm 58 \cdot 2$ & $162 \cdot 6 \pm 48 \cdot 1$ \\
\hline Urinary potassium (24-hr output mmol) & $83.5 \pm 61.5$ & $80 \cdot 1 \pm 25 \cdot 5$ & $66.9 \pm 20$ & $68.2 \pm 21 \cdot 7$ \\
\hline Urinary sodium/potassium ratio & $2.68 \pm 1.08$ & $1.82 \pm 1.09 \dagger$ & $2.96 \pm 1.39$ & $2.84 \pm 1.33$ \\
\hline Number of patients with normal blood pressure & \multicolumn{2}{|c|}{$11(32 \%) \ddagger$} & \multicolumn{2}{|c|}{$2(11 \%)$} \\
\hline
\end{tabular}

* $P<0.01 ; \nmid P<0.001 ; \ddagger P<0.001$ (Chi-squared statistic).

The response according to ethnic group to the modified dietary regime is shown in Table 4. Both white and West Indian groups demonstrated a significant fall in diastolic blood pressure, which was accompanied by a significant fall of urinary sodium excretion, but only the whites showed a significant fall in sodium/potassium ratio. However, in the West Indian group, both the initial mean urinary sodium output and urinary sodium/potassium ratio were lower than both whites and Asians, although this did not reach statistical significance.

The Asian group demonstrated no significant changes in blood pressure although there was a greater fall in urinary sodium output and diastolic blood pressure when compared to control. In the Asian patients, $56 \%(n=5)$ showed either an increase or no change in urinary sodium output, in contrast to the West Indian group at $33 \%(n=3)$ and the whites at $31 \%(n=5)$.

Most patients complained that the modified dietary regimen was bland but the protocol has now been extended to a 3-month period so that assessment of compliance and the effects of this dietary regimen on diabetic control can also be made.

\section{Discussion}

The important finding of this study is a significant fall in diastolic blood pressure on the modified dietary regimen which was also observed in both the West Indian and white diabetic hypertensive patient groups when compared to control. These findings are in agreement with similar studies in the non-diabetic essential hypertensive patients (Dodson et al., 1981a; Beard et al., 1982; MacGregor et al., 1982a). In particular, Beard et al. reported a reduction in antihypertensive drug therapy on a similar dietary regimen. In our study, a significant number of patients had normal blood pressure after 1-months treatment on the modified diet, therefore reducing the number of patients who would have otherwise received anti-hypertensive drug therapy.

The fall in diastolic blood pressure was associated with significant changes in urinary sodium output. Previous studies have shown a relationship between sodium intake and blood pressure and it seems likely that the fall in blood pressure in our group may relate to the low sodium aspect of the diet. However, the other aspects may also be responsible for the hypotensive effect. These may include the low fat aspect of 
TABLE 4. Changes in blood pressure, weight and urinary sodium excretion in the diet-treated group according to ethnic group (mean \pm s.d.

\begin{tabular}{|c|c|c|c|c|c|c|}
\hline & \multicolumn{2}{|c|}{ White $(n=16)$} & \multicolumn{2}{|c|}{ West Indians $(n=9)$} & \multicolumn{2}{|c|}{ Asians $(n=9)$} \\
\hline & 0 & 1 month & 0 & 1 month & 0 & 1 month \\
\hline \multirow{3}{*}{$\begin{array}{l}\text { Systolic blood pressure (mmHg) } \\
\text { Diastolic blood pressure (mmHg) } \\
\text { Urinary sodium (24-hr output, } \\
\text { mmol) }\end{array}$} & $175 \cdot 6 \pm 13.5$ & $172 \cdot 8 \pm 17 \cdot 8$ & $179.7 \pm 37.7$ & $164 \pm 24 \cdot 1$ & $164 \cdot 1 \pm 23 \cdot 6$ & $165 \cdot 8 \pm 29 \cdot 9$ \\
\hline & $97 \cdot 6 \pm 9 \cdot 0$ & $92.6 \pm 9.9 *$ & $100 \cdot 3 \pm 9 \cdot 7$ & $90.5 \pm 8.3 \dagger$ & $97.8 \pm 9.5$ & $92.4 \pm 8.96$ \\
\hline & $214 \cdot 9 \pm 93 \cdot 2$ & $139 \pm 77 \cdot 5+$ & $152 \cdot 6 \pm 70 \cdot 8$ & $115 \cdot 8 \pm 67 \cdot 7$ & $\pm 55 \cdot 7$ & $\pm 55 \cdot 4$ \\
\hline Urinary sodium/potassium ratio & $2 \cdot 8 \pm 1 \cdot 2$ & $1.6 \pm 0.9 \ddagger$ & $2 \cdot 19 \pm 0.98$ & $1.61 \pm 0.58$ & $2.96 \pm 1.0$ & $2.45 \pm 1.6$ \\
\hline Patients with normal blood pressure & 5 & $1 \%)^{*}$ & & $6 \%) \ddagger$ & & $33 \%)$ \\
\hline
\end{tabular}

${ }^{*} P<0.05 ; \dagger P<0.01 ; \ddagger P<0.001$.

The number of patients with normal blood pressure after 1 month in the control group was $11 \%$ (see Table 3 ).

the dietary regimen which has been reported by Puska et al. (1983) to be hypotensive, and the high fibre intake, as Rouse et al. (1983) has demonstrated the hypotensive effect of a vegetarian diet. It has also been previously reported that black hypertensive patients appear to have a poorer response to antihypertensive medication than whites and it has been suggested that this may be due to poor compliance or low socio-economic status (HDFP Co-operative Study, 1977). However, it is clear from this study that a similar significant hypotensive response associated with a fall in urinary sodium output was observed in both white and West Indian ethnic groups, suggesting similar compliance. Luft et al. (1977) has shown that normotensive blacks following a sodium load excrete significatly less sodium and potassium than did matched whites. It is therefore of note that the initial urinary sodium output of the black group was lower than both whites and Asians, although this did not reach statistical significance.

The Asian group demonstrated no significant results in the study although a fall in diastolic blood pressure and urinary sodium output was observed. The reason for this is not clear although we suspect that it was a combination of poor compliance and understanding of the dietary protocol.

We conclude that a high fibre, low fat and low sodium dietary regimen may have a hypotensive response after a period of 1 month, and that there is a similar response in both black and white diabetic hypertensive patients. Further observations on these patients will determine the response, compliance, and whether this dietary regimen will obviate or reduce the need for anti-hypertensive drug therapy in the long-term.

\section{Acknowledgments}

P. Pacy is a Wellcome Research Fellow. We are grateful to: Mr A. J. Kubicki for technical assistance, Miss L. Walker and Mrs S. Bradley for assistance with dietary counselling, the staff of the Clinical Investigation Unit, Mrs B. Singh for secretarial help, and
Pasta Foods Ltd. for supplying durum hard wheat bran for 角 patients.

\section{References}

Barrett-Connor, E., Criqui, M.H., Klauber, M.R. \& Hol BROOK, M. (1981) Diabetes and hypertension in a communityof older adults. American Journal of Epidemiology, 133, 276.

BEARD, T.C., COOKE, H.M., GRAY, W.R. \& BARGE, R. (1983) Randomised controlled trial of a no-added sodium diet for $\mathrm{m}$ +f hypertension. Lancet, ii, 455.

Christlieb, A.R., Warram, J.H., Krolewski, A.S., Busik, E.D, GANDA, O.P., ASMal, A.C., SOELDNER, J.S. \& BRADLeY, R. (1981) Hypertension: the major risk factor in juvenile-onget insulin-dependent diabetics. Diabetes, 30, (Suppl. 2), 90.

Dodson, P.M. \& HuMPHREYS, D.M. (1981a) Hypertensiomand angina. In: Western Diseases: their emergence and preventionf Trowell, H.C. \& Burkitt, D.P.), p. 411. Edward Arnold, Lomden. Dodson, P.M., Stocks, J., Holdsworth, G. \& Galtonģ]ذ (1981b) High fibre and low-fat diets in diabetes mellitus. Journal of Nutrition, 46, 289.

HELMER, O.M. \& JUDSON, W.E. (1968) Metabolic studies hypertensive patients with suppressed plasma renin activity mot due to hyperaldosteronism. Circulation, 38, 965.

HDFP (HYPERTENSION DETECTION AND FOLLOW-UP PROGRAM CO OPERATIVE GROUP) (1977) Blood pressure studies in 14 commuAties. Journal of the American Medical Association, 237, 2385.

KEIHM, T.G., ANDERSON, J.W. \& WARD, K. (1976) Beneficial effecis of a high carbohydrate, high fibre diet on hyperglycaemic diabertic men. American Journal of Clinical Nutrition, 29, 895.

LUFT, F.C., GRIM, C.E., HIGGINS, J.T. \& WEINBERGER, M.H. (1977) Differences in response to sodium administration in normotensiue white and black subjects. Journal of Laboratory and Clinical Medicine, 90, 555.

MaCGregor, G.A., MARKANDU, N.D., BeSt, F.E., Elder, D.M. CAM, J.M., Sagnella, G.A. \& SQuires, M. (1982a) Double blifi randomised crossover trial of moderate sodium restriction. Lanegt, i, 351 .

MACGRegor, G.A., SMith, S.J., Markandu, N.D., Banks, R.A.용 SAGNELlA, G.A. (1982b) Moderate potassium supplementationji essential hypertension. Lancet, ii, 567.

Morgan, T., Gillies, A., Adam, W., Wilson, M., Morgan, G. CARNEY, S. (1978) Hypertension treated by salt restrictiof Lancet, i, 227.

Puska, P., Iancono, J., Nissinen, A., Korhonen, H., Vartiaine E., Pietinen, P., Dougherty, R., Leino, V., Mutanen, MU MoIsio, S. \& HuTtunEN, J. (1983) Controlled randomised trialo the effect of dietary fat on blood pressure. Lancet, $\mathbf{i}, 1$.

Rouse, I.L., BeILIN, L.J., ARMSTRONG, B.K. \& VANDONGEN, $\mathbf{B}$ (1983) Blood pressure-lowering effect of a vegetarian dist: controlled trial in normotensive subjects. Lancet, i, 5 . 